\title{
(1)
}

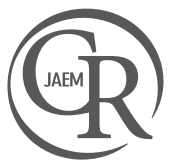

\section{Afflictive Effect of Squirting Cucumber: Isolated Uvular Oedema due to Complication of a Herbal Medicine}

\author{
Acı Kavunun Acı Etkisi: Bitkisel Tedavi Komplikasyonunu Içeren İzole Uvular Ödem
}

Nurettin Özgür Doğan, Gül Pamukçu Günaydın, Mustafa Tekin, Yunsur Çevik

Etlik Ihtisas Eğitim ve Araştırma Hastanesi, Acil Tıp Kliniği, Ankara, Türkiye

\section{ABSTRACT}

Ecballium elaterium, whose juice is used for the symptomatic treatment of rhinosinusitis in folk medicine, has been reported as causing significant allergic reactions including upper airway oedema. Due to its strong anti-inflammatory effects, the juice is widely used by people in the eastern Mediterranean region. A 57 year old healthy man presented to the emergency department with dysphagia and severe uvular oedema. He had dripped the juice of Ecballium elaterium intranasally for the symptomatic treatment of his rhinosinusitis, which was caused by an allergic reaction and presented with dysphagia and dyspnea. Emergency physicians should be familiar with the adverse effects of herbal remedies, which have been frequently used in folk medicine.

Keywords: Ecballium elaterium, rhinosinusitis, emergency department

Received: 06.02.2012 Accepted: 03.04.2012

\section{ÖZET}

Suyu halk tıbbında rinosinüzitin semptomatik tedavisinde kullanılan Ecballium elaterium ile ilgili olarak, içinde havayolu ödeminin de olduğu bazı ciddi alerjik reaksiyonlar bildirilmiştir. Meyvenin suyu, güçlü antiinflamatuar etkilerine bağlı olarak, doğu akdeniz bölgesinde yaşayan insanlar tarafından yaygın kullanılır. Elli yedi yaşında sağlıklı erkek, acil servise yutma güçlüğü ve ciddi uvula ödemi ile başvurdu. Hasta, semptomatik rinosinüzit tedavisi için Ecballium elaterium meyvesinin suyunu burun yoluyla damlatmış, bu da nefes darlığı ve yutma güçlüğü ile sonuçlanan alerjik bir reaksiyona neden olmuştu. Acil tıp hekimleri, halk tıbbında sıkça kullanılan bitkisel ilaçların yan etkilerine aşina olmalıdırlar.

Anahtar Kelimeler: Ecballium elaterium, rinosinüzit, acil servis Geliş Tarihi: 06.02.2012 Kabul Tarihi: 03.04.2012

\section{Giriş}

Bilimsel adı Ecballium elaterium olarak geçen ve halk arasında cırtatan, acı dülek, eşek hıyarı, şeytan keleği, yabani kavun olarak da bilinen acı kavun, Cucurbitaceae ailesine mensup bir bitki türüdür (1). Meyvesi oval yapıda, 3-5 cm çapında, sarı-yeşil renkte, üzeri tüylü ve Akdeniz coğrafyası ile Anadolu'da yaygın olarak yetişen bir bitkidir $(2,3)$.

Halk tababetinde en yaygın kullanılma sebebi kronik sinüzit tedavisinde suyunun burun deliklerinden bir-iki damla şeklinde uygulanması olsa da; hepatit tedavisinde ve kulak ağrısında suyu lokal olarak, hemoroid tedavisinde ve idrar inkontinansında ise kökleri yutularak kullanılmaktadır (1).

Meyvenin suyu, halk arasında tedavi amaçlı olarak genellikle dilüe edilerek kullanılır. Uygun dilüsyon yapılmaması hayatı tehdit eden alerjik reaksiyonlara yol açabilir (4). Bizim sunduğumuz vaka da kronik sinüzit için nazal yolla ecballium elaterium'un meyvesinin suyunu kullanan ve buna bağlı ciddi uvula ödemi gelişmiş olan bir olgudur. 


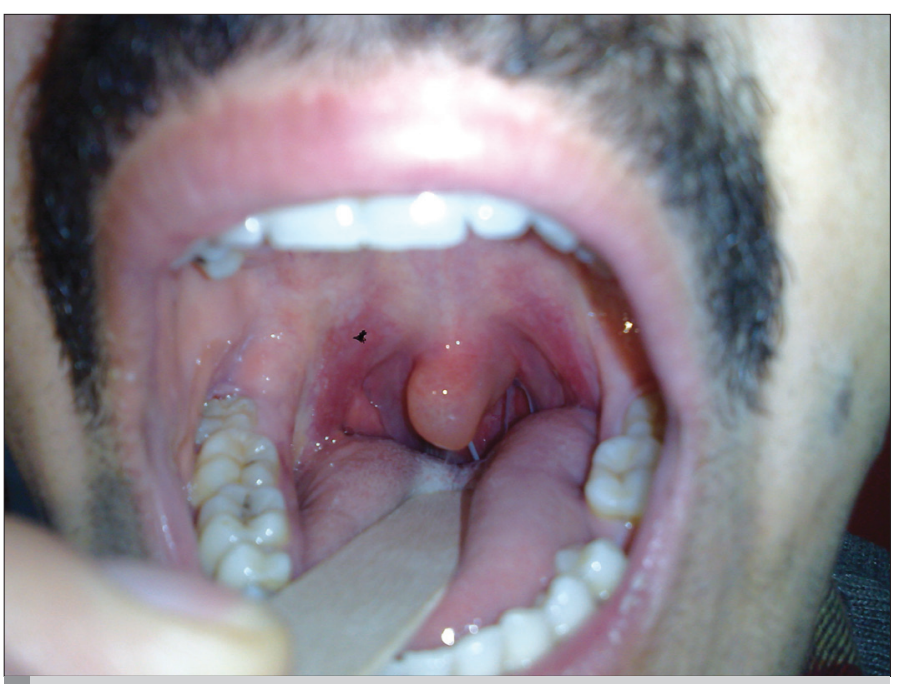

Resim 1. Hastanın fizik muayenesinde izlenen belirgin izole uvula ödemi

\section{Olgu Sunumu}

Elli yedi yaşında erkek hasta acil servise yutma güçlüğü, boğazda takılma hissi ve nefes darlığı yakınmalarıyla başvurdu. Hastanın hikayesinde kronik sinüziti olduğu ve buna bağlı son günlerde burun tıkanıklığı ve burun akıntısı şikayetlerinde artış olduğu öğrenildi. Özgeçmişinde kronik sinüzit dışında bilinen hastalığı ve ilaç kullanımı olmayan hastanın, öncesine ait alerjik reaksiyon öyküsü de yoktu.

Hasta başvurusundan önce sinüzitle ilgili yakınmalarına iyi geldiği ve burun tıkanıklığını açacağı düşüncesiyle, her iki burun deliğinden altışar damla acı kavun meyvesinin suyundan seyreltme yapmaksızın damlatmıştı. Hikayesinden, acı kavun meyvesini burun tıkanıklığı için ilk kez kullandığı ve kullanımını çevresinden duyduğu öğrenildi.

Hastanın fizik muayenesinde genel durumu iyi, vital bulguları stabildi. Kan basıncı 140/90 mmHg, nabzı 84 atım/dakika, solunum hızı 18/dakika olarak saptandı. Bunlarla birlikte burun ve farinks duvarının hiperemik görünümde olduğu, uvulasının belirgin ödemli olduğu izlendi (Resim 1), bronkospazmı ve ürtikeryal döküntüleri yoktu. Hastanın diğer sistem muayenelerinde herhangi bir anormalliğe rastlanmadı.

Bakılan böbrek fonksiyon testleri ve kan elektrolit değerleri normal sınırlar içinde gelen hastaya, aralıklı olarak toplam 200 mg metilprednizolon, 50 mg difenhidramin ve 100 mg ranitidin intravenöz yoldan; 0.3 mg adrenalin intramusküler yoldan uygulandı, 4 L/dk oksijen verildi. On iki saat boyunca acil serviste izlenen hasta, yutma güçlüğünün ve uvula ödeminin gerilemesi üzerine acil servisten önerilerle taburcu edildi.

\section{Tartışma}

Ecballium elaterium, içeriğindeki aktif madde elaterin aracılığıyla etki gösteren güçlü purgatif ajanı içeren bir bitkidir. Elaterin, muköz membranlarda su geçirgenliğinde yaptığı değişiklikler nedeniyle akciğer ödemi ve asit tedavisinde kullanılmıştır. Bitki bu nedenle, Akdeniz toplumlarında sinüzitin semptomatik tedavisinde tercih edilen bir "halk ilacı"dır (2). Yıllarca güvenle kullanılmış olmasına rağmen, allerjiye yatkın kişilerde hayatı tehdit eden dil, dudak ve uvular ödeme yol açabilir (5). Olgumuzda öncesine ait bilinen allerji öyküsü olmamaşına karşın, belirgin uvula ödemi gelişmiş ve bu da yutma güçlüğüne yol açmıştır.

Literatürde olgu sayısı bakımından en geniş seri olan Kloutsos ve ark.'larının (5) yapmış oldukları retrospektif çalışmanın sonuçlarına göre, kliniklerine dört yıllık süre içinde ecballium elaterium maruziyeti sonrasında başvuran 42 hastanın 20'sinde uvular ödem tespit edilmiştir. Dil, ağız mukozası ve periorbital bölgede de anjiyoödem tablosu izlenmekle birlikte, uvular ödemi olan hastalarda ödemin diğer yumuşak doku yapılarına ilerlememiş olduğu izlenmiştir; sistemik reaksiyon görülmemiştir. Hastamızda da önde gelen semptom uvular ödeme bağlı yutma güçlüğüdür, yapılan muayenesinde diğer dokularda alerjik reaksiyon belirtileri izlenmemiş, sistemik anaflaktik reaksiyon gelişmemiştir.

Böbrek yetmezliği gibi sistemik komplikasyonlar, genellikle bitkinin içerdiği alkaloid resinler ve glikozitlere bağlanmıştır (4). Hastamızda böbrek fonksiyonlarında herhangi bir anormallik saptanmamış olmakla birlikte, Ecballium elaterium'a bağlı ciddi renal ve kardiyak toksisite belirtilerinin gösterildiği yayınlar da mevcuttur (6).

Ecballium elaterium ile ilgili olgu sunumu şeklindeki literatür kaynakları, gelişen reaksiyonun bitkisel toksine karşı alerjik bir durum olduğunu işaret etmektedir. Bu vakalarda uvular ödem, dil ödemi gibi lokal sayılabilecek komplikasyonlarla birlikte, izole periorbital ödem gibi daha uzak dokulardaki immün reaksiyonlara rastlamak da mümkündür (7). Buna karşın kronik sinüzit tedavisi nedeniyle ecballium elaterium meyvesinin suyunu kullanan bir olguda lokal nekrotik reaksiyon geliştiğini öne süren bir yayın da mevcuttur (2). Ecballium elaterium'un lokal toksik etkilerinin incelenmesi için daha geniş sayıda olguların bulunduğu çalışmalara ihtiyaç vardır.

\section{Sonuç}

Solunum sıkıntısı ve yutma güçlüğü ile acil servise başvuran hastalarda, alerjik doku reaksiyonlarına neden olabilecek lokal bitkisel ajanların kullanımı sorgulanmalı ve oral mukozaların muayenesi dikkatle yapılmalıdır. Acil tıp hekimleri, halk arasında yaygın kullanılan bitkisel tedavi yöntemlerinin yan etkilerine aşina olmaIıdırlar.

\section{Çıkar Çatışması}

Yazarlar herhangi bir çıkar çatışması bildirmemişlerdir.

\section{Kaynaklar}

1. Kültür S. Medicinal plants used in Kirklareli Province (Turkey). J Ethnopharmacol. 2007; 111: 341-64. [Crossref]

2. Eken C, Özbek K, Yıldırım CK, Eray O. Severe uvular edema and nasal mucosal necrosis due to Ecbalium elaterium (squirting cucumber): 
an allergic reaction or direct toxic effect? Clin Toxicol (Phila) 2008; 46: 257-8. [Crossref]

3. Pekdemir M, Yıldız M, Durukan P. Ecbalium elaterium'a bağlı uvular ödem gelişmiş bir olgunun geç başvurusu. Tr J Emerg Med 2005; 5: 196-8.

4. Satar S, Gokel Y, Toprak N, Sebe A. Life-threatening uvular angioedema caused by Ecbalium elaterium. Eur J Emerg Med 2001; 8: 337-9. [Crossref]
5. Kloutsos G, Balatsouras DG, Kaberos AC, Kandiloros D, Ferekidis E, Economou C. Upper airway edema resulting from use of Ecbalium Elaterium. Laryngoscope 2001; 111: 1652-5. [Crossref]

6. Vlachos P, Kanitsakis NN, Kokonas N. Fatal cardiac and renal failure due to Ecbalium elaterium (squirting cucumber). J Toxicol Clin Toxicol 1994; 32: 737-8. [Crossref]

7. Kavalcı C, Durukan P, Çevik Y, Özer M. Angioedema due to ecballium elaterium: case report. JAEM 2007; 5: 39-40. 